\title{
The Role of the Binder Phase in the WC-Co Sintering
}

\author{
A.G.P. da Silva ${ }^{\mathrm{a}^{*}}$, W.D. Schubert ${ }^{\mathrm{b}}$, B. Lux ${ }^{\mathrm{b}}$ \\ ${ }^{a}$ Departamento de Física, Universidade Federal do Rio Grande do Norte, \\ 59072-970 Natal - RN, Brasil \\ ${ }^{\mathrm{b}}$ Institut für chemische Technologie anorganischer Stoffe, Technische Universität \\ Wien, Getreidemarkt, 9/161, A-1060, Vienna, Austria
}

Received: November 16, 2000; Revised: April 27, 2001

\begin{abstract}
The sintering of hardmetal in the solid state is studied. The influence of the WC particle size on the sintering kinetics, the role of the binder phase in the densification process and how sintering depends on the heating conditions are investigated. It is observed that alloys with different WC particle size show quite different structural evolution during sintering, although the densification mechanisms are the same. This is explained by the formation of agglomerates of WC and Co. Hardmetal alloys can sinter very rapidly when high heating rates are used, since rapid heating accelerates the binder spreading and the formation of WC-Co agglomerates. The binder phase (Co) spreads on the WC particles initially as a thin layer. Subsequently, more Co spreads on this layer and WC-Co agglomerates are formed.
\end{abstract}

Keywords: sintering, hardmetal, cobalt

\section{Introduction}

Hardmetal alloys are a typical example of a composite material. Their most simple constitution is a hard phase, tungsten carbide, together with a metal which plays the role of binder. Cobalt is the most frequently used metal, but nickel can also be used. This material exhibits high hardness, maintaining an elevated strength level. Furthermore, hardness and strength can be easily adjusted by varying the alloy's composition. For instance, the higher the WC content the harder is the alloy. The final alloy's properties are a combination of the properties of the individual constituents. In some cases, small amounts of other refractory carbides are added to inhibit the WC grain coarsening during sintering, but they do not directly affect the alloy's properties.

Tungsten carbide is not the hardest carbide nor is Co the toughest metal, but WC-Co is the best system for hardmetals. The reason for this is the outstanding coupling between WC and Co, represented by: (1) the low dihedral angle of the system WC-Co, which is reported to be zero ${ }^{1}$; (2) Co dissolves a significant amount of WC, but WC does not dissolve $\mathrm{Co}^{2}$; (3) this system has an ternary eutectic reaction at $1275^{\circ} \mathrm{C}$. Characteristics (1) and (2) contribute to the good sinterability of the WC-Co, compared to other systems. They also help to increase the adherence between the WC and Co phases, improving the mechanical properties. The third characteristic allows this system to be sin- tered at temperatures significantly lower than the melting point of $\mathrm{Co}$ and the sintering temperature of other similar systems.

Hardmetal alloys are sintered in a "liquid phase environment" but significant shrinkage takes place in the solid state. As early as 1944, Dawihl and Schroeter ${ }^{3}$ reported that full density could be reached by sintering a piece at $1250{ }^{\circ} \mathrm{C}$ for $80 \mathrm{~h}$. Later on, Exner ${ }^{4}$ and Bock ${ }^{5}$ reported that around $90 \%$ of the alloy's relative density could be obtained during the heating stage. Milner and co-workers ${ }^{6-9}$ have proposed a model for the solid phase sintering of WC-Co hardmetal, which was extended by da Silva ${ }^{10}$. According to Milner et al., solid state sintering proceeds in three stages: (1) Co spreads over the WC particles and covers the surface of the particles; (2) the spreading Co agglomerates neighboring WC particles, acting like a cement and; (3) the resulting agglomerates form a network and sinter together as large particles.

In the sintering of hardmetal, the binder phase plays the most significant role. It is responsible for densification through wetting, spreading and formation of agglomerates. The hard phase has a passive role, since the WC particles do not sinter together but are moved by the binder.

This work focus on the role of the binder phase in hardmetal sintering. It investigates how the binder contributes to sintering and how this contribution depends on 
several parameters of the material, such as the mean WC particle size and the heating conditions.

\section{Materials and Methods}

The characteristics of the starting powders used in the work are shown in Table 1. The WC powders were supplied by the Company Wolfram Bergbau und Hütten Gesellschaft (Austria). The Co powder was supplied by H.C. Starck (Germany).

Two alloy grades were prepared with these powders through the powder metallurgical route for hardmetal production, that is, ball milling, granulation, presintering-dewaxing and sintering. Table 2 gives details of the alloys. Alloy G2 was milled for short time to avoid the size reduction of the WC particles.

All samples were sintered in a furnace coupled to a dilatometer under a vacuum of about $10^{-3}$ mbar. Some samples were sintered by using a temperature program consisting of two heating stages of $10{ }^{\circ} \mathrm{C} / \mathrm{min}$ from room temperature up to $800^{\circ} \mathrm{C}$ and $3{ }^{\circ} \mathrm{C} / \mathrm{min}$ up to $1400^{\circ} \mathrm{C} / \mathrm{min}$., with a soaking time of $1 \mathrm{~h}$ at $1400{ }^{\circ} \mathrm{C}$. After sintering, the samples are cut, embedded, ground, polished and etched for observation of their structures. This kind of sintering shows the shrinkage behavior and the shrinkage rate through dilatometry. All samples sintered in this way showed only two phases (WC and Co), indicating the right carbon balance of the alloys.

Other samples were sintered at intermediate temperatures, between $700{ }^{\circ} \mathrm{C}$ and $1400{ }^{\circ} \mathrm{C}$ (without isotherm), to follow the structure development step by step during sintering. The samples are then fractured and observed by SEM.

Special experiments were planned to determine how the binder phase spreads over the carbide surface. Co particles were poured on a mirror polished flat surface of a pure hot pressed WC plate and quickly heated up to $1250{ }^{\circ} \mathrm{C}$ by pushing the sample in a boat up to the hot zone of a furnace pre-set at that temperature. The experiment was carried out under a $\mathrm{H}_{2}$ flow. A thermocouple installed in the boat

Table 1. Characteristics of the WC and Co powders. SEM and FSSS are measurement techniques.

\begin{tabular}{lcc}
\hline Powder & Mean particle size, $\mu \mathrm{m}$ & Chemical composition \\
\hline WC fine & 0.2 (SEM) & $\mathrm{C}_{\text {total }} 6.25 \mathrm{wt} . \%$ \\
& & Cfree $0.17 \mathrm{wt} . \%$ \\
& Oxygen $0.12 \mathrm{wt} \%$ \\
WC coarse & 25 (FSSS) & $\mathrm{C}_{\text {total }} 6.18 \mathrm{wt} . \%$ \\
& & $\mathrm{C}_{\text {free }} 0.05 \mathrm{wt} . \%$ \\
Co & 0.95 (FSSS) & Oxygen $0.006 \mathrm{wt} . \%$ \\
\hline
\end{tabular}

Table 2. Alloy grades prepared.

\begin{tabular}{lccc}
\hline Alloys & Composition & Powders & Milling \\
\hline G1 & WC-10wt.\%Co & WC fine, Co & $90 \mathrm{~h}$ \\
G2 & WC-10wt.\%Co & WC coarse, Co & $4 \mathrm{~h}$ \\
\hline
\end{tabular}

measured the actual temperature that was never above $1250{ }^{\circ} \mathrm{C}$. In less than one minute the final temperature is reached. The samples were kept for 3 minutes in the hot zone and then quenched by withdrawing to the cooling zone. The particles and plate are then observed under a scanning electron microscope. Powder compacts were also sintered under these heating conditions.

\section{Results}

Figures 1 and 2 show SEM images of fracture surfaces of alloys G1 and G2, sintered at intermediate temperatures (interrupted sintering).

In order to compare the shrinkage behaviour of the two alloys, the percent shrinkage was employed, since the absolute shrinkage depends on the sample dimensions. The percent shrinkage varies from zero, at the beginning of the sintering cycle, to $100 \%$ at the end of the cycle. Figures 3 and 4 show dilatometric curves of alloys G1 and G2 for percent shrinkage and percent shrinkage rate respectively.

Figure 5 shows the result of the Co spreading on the flat WC surface after fast heating up to $1250{ }^{\circ} \mathrm{C}$. Around the actual particles, it is possible to see a spot, like a shadow. It is a cobalt layer spreading over the WC surface.

\section{Discussion}

The binder plays an active role in hardmetal sintering. It is in fact responsible for the densification since it is more sensitive to temperature than the carbide in both solid and liquid phase sintering. For instance, it can diffuse faster. The initial structure of the sample (the green body structure) consists of a porous body in which particles of $\mathrm{WC}$ and $\mathrm{Co}$ are mixed and in contact with each other. The final sintered structure is dense, consisting of faceted WC grains embedded in a Co matrix. The matrix phase surrounds most of the WC grains, separating them from each other. During sintering, the pores are closed, the WC particles change their shape and the binder phase spreads throughout the structure. According to Milner et al. ${ }^{6-9}$, Co initially wets and spreads over the surface of the WC particles. Next, it forms agglomerates when it pulls the WC particles close to

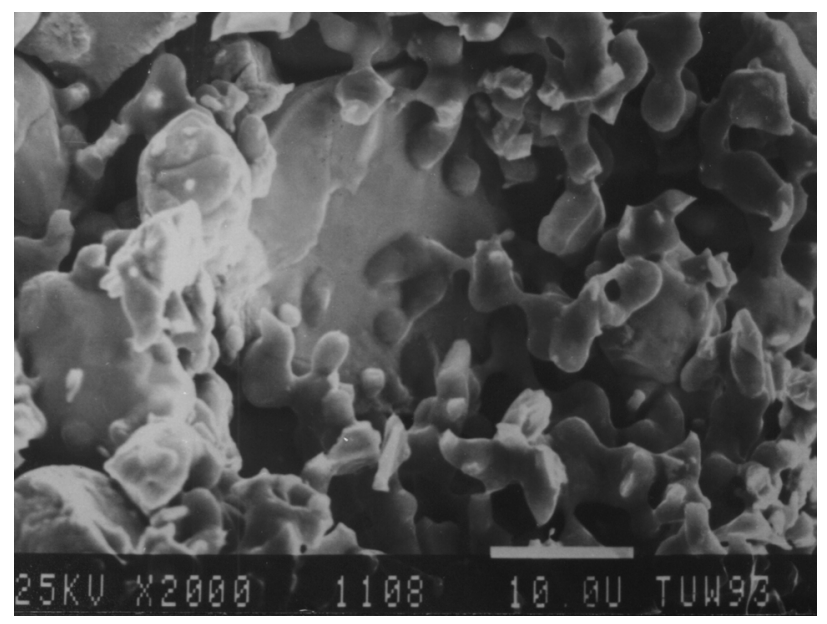

Figures 1. SEM images of alloy G2 sintered at $1120^{\circ} \mathrm{C}$. 


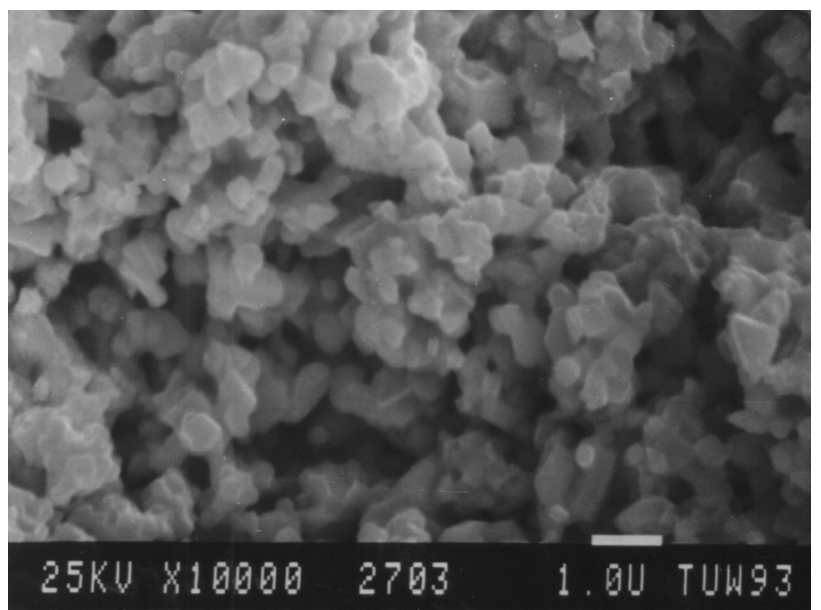

Figure 2. SEM images of alloy G1 sintered at $1200{ }^{\circ} \mathrm{C}$.

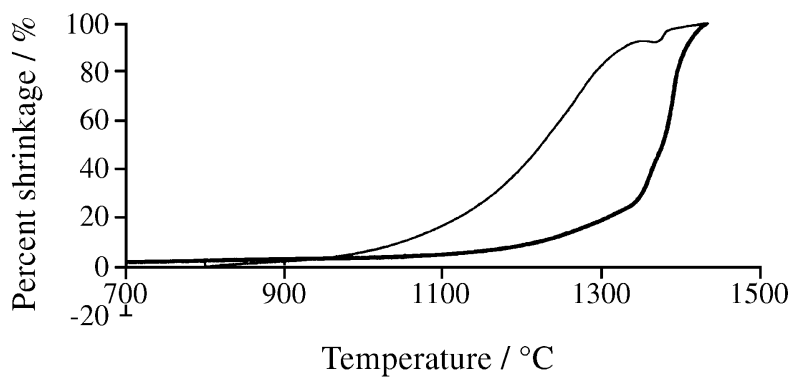

— Alloy G1 — Alloy G2

Figure 3. Percent shrinkage of alloys G1 and G2.

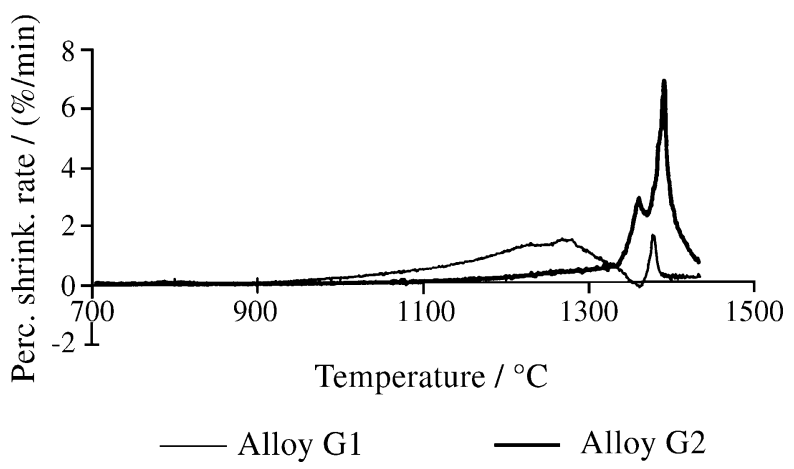

Figure 4. Percent shrinkage rate of alloys G1 and G2.

each other. This stage of sintering is accompanied by shrinkage.

Figures 1 and 2 show these two stages of sintering. Figure 1 is an early stage of solid state sintering of alloy G2 (coarse WC). It shows Co wetting and spreading over the large WC particles at $1120^{\circ} \mathrm{C}$. For alloy G1 (fine WC), shown in Fig. 2 , at $1200^{\circ} \mathrm{C}$, the agglomerates can be clearly seen. At this stage, the microstructure of alloy G1 consists of a network of WC-Co agglomerates.

The microstructures of alloys G1 and G2 look quite different, although the sintering mechanism for both alloys is the same. This difference can also be seen in the dilatometric curves for shrinkage and shrinkage rate (Figs. 3

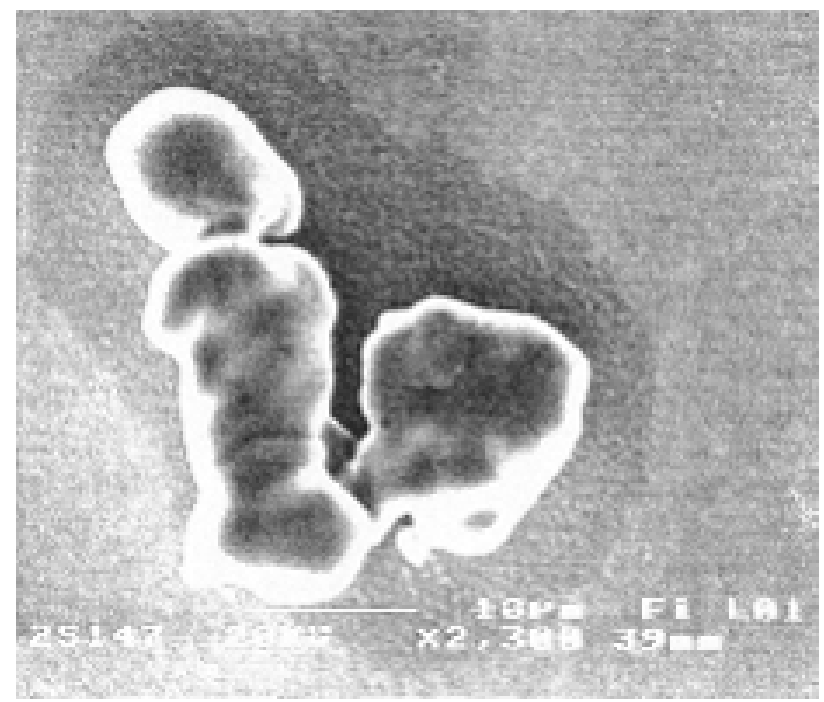

Figure 5. SEM image of Co particles on a WC surface after fast heating up to $1250{ }^{\circ} \mathrm{C}$. The darker region surrounding the Co particles is a Co layer spreading over the carbide surface.

and 4). Alloy G1 sinters much faster than alloy G2. Alloy $\mathrm{G} 1$ begins to shrink at around $800^{\circ} \mathrm{C}$. At $1300^{\circ} \mathrm{C}$, this alloy reaches almost $80 \%$ of the whole densification whilst alloy G2 reaches a bit less than $20 \%$ at the same temperature. At $1300{ }^{\circ} \mathrm{C}$, sintering can still be considered to proceed in solid state. Alloy G2 sinters rapidly only above $1320^{\circ} \mathrm{C}$, when a liquid phase is formed in large amount.

Experiments specially designed for studying the Co spreading on WC under conditions of fast heating show how Co actually spreads and how fast Co can respond to the temperature increase. Figure 5 is a SEM image of some Co particles on a WC flat surface after fast heating up to $1250{ }^{\circ} \mathrm{C}$. Three regions are clearly seen: the Co particles in the center, a darker region surrounding the particles and a bright region, which is the WC surface. The dark spot surrounding the Co particles is a thin Co layer as shown by EDS measurements. This result shows how Co spreads on WC. Initially, a thin Co film spreads on the WC surface and covers it. Then the Co particles spread on this film. The spreading velocity of the film increases as the heating rate increases. A powder compact sintered under the same fast heating conditions exhibited a microstructure comparable to that of a sample sintered at $1250{ }^{\circ} \mathrm{C}$, under the slow heating condition. This shows that this spreading mechanism is also able to promote rapid densification. The Co spreading begins as early as $800{ }^{\circ} \mathrm{C}$ because at this temperature alloy $\mathrm{G} 1$ begins to shrink.

Although the sintering mechanism is the same for both alloys, the sintered microstructures of the alloys develop differently. Parameters such as the WC mean particle size influence the sintering kinetics, as shown by the dilatometric curves. The WC particle size influences the mixture dispersion, the pore size and the coordination number of each Co particle. The number of WC particles surrounding each Co particle decreases and the pore size increases as the mean WC particle size increases. In a green structure, consisting of small Co particles and large WC particles, the Co particles would preferentially occupy the pores between 
the WC particles, forming Co agglomerates. As a consequence of this, the number of contacts between $\mathrm{WC}$ and $\mathrm{Co}$ particles decreases as the WC mean size increases. Under such conditions, Co has to travel long distances to wet and cover different WC particles, forming a WC-Co agglomerate. Furthermore, the formation of WC-Co agglomerates depends on the movement (including rotation and sliding) of the WC particles closer to each other due to the action of capillary forces, caused by the Co links between the WC particles. Large WC particles are more difficult to move than small ones. If the WC particles are small, Co can wet and cover several WC particles, moving along relatively short distances and the capillary forces can move the small particles more easily. Thus the WC-Co agglomerates with fine WC particles are more easily formed than in the case of coarse WC particles.

In every site where a Co particle lies, a WC-Co agglomerate is formed. The movement of WC particles to the center of the agglomerate forms a large peripheral porosity around each agglomerate. As the agglomerates grow in size, Co necks link them together and a network is formed. The larger the agglomerates the larger is the peripheral porosity. The size of the agglomerates is co-determined by the WC particle size. The closure of the peripheral porosity depends on the deformation of the agglomerates and on the enlargement of the contact area between them. The larger the peripheral porosity the slower this stage proceeds. Figure 6 shows schematically how solid state sintering proceeds.

In general, the structure is porous when the liquid phase is formed, at the eutectic temperature, and the porosity volume and mean size depend on the WC mean particle size. The liquid phase is then responsible for closing the remaining porosity. Liquid can penetrate more easily into the pores. The overall viscosity of the system (viscosity of the mixture WC and binder) decreases and the agglomerates can deform more easily under the action of the capillary forces. However, if the pores are very large, even the liquid phase cannot completely close the pores and the structure will consist of large, round and isolated pores after sintering.

\section{Conclusions}

The experiments reveal details about hardmetal solid state sintering, such as the mechanism of sintering, how it depends on the WC particle size and how the binder phase spreads on the WC surfaces.

The model proposed by Milner and co-workers is quite suitable to describe hardmetal solid state sintering, but depending on certain parameters the evolution of the structure can differ significantly. The WC particle size changes the kinetics of the agglomerate formation and determine the size of the peripheral porosity. The larger the WC particles the more difficult is the agglomeration and the larger is the porosity around the agglomerates.

The agglomerates are formed basically due to the binder mobility. The binder initially spreads on the WC particles as a thin layer. The bulk of the binder then spreads on this layer and forms the WC-Co agglomerates. The binder can

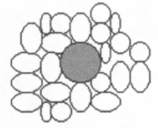

(a)

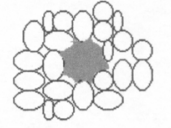

(b)

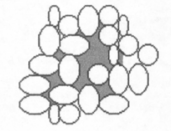

(c)

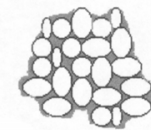

(d)

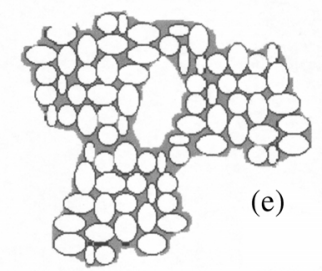

Figure 6. Schematic of the hardmetal solid state sintering mechanism: a) in the green body, around each Co particle there is a group of WC particles; b) a thin Co layer spreads over the WC particles and the bulk of Co particles begin to cover and link the neighbors WC particles; c) as Co spreads further, a WC-Co agglomerate is formed; d) dense WC-Co agglomerates are formed; e) at this point, the agglomerates touch each other and the structure consists of a network of agglomerates that sinter as large particles. A large peripheral porosity exists between the agglomerates.

spread very rapidly and the spreading velocity depends on the heating rate. The structure can densify even if very high heating rates are used.

Most of the densification can occur before liquid formation, depending on certain parameters such as the WC particle size, but frequently pores remain in the structure, which are closed when the liquid phase is formed. For hardmetal alloys prepared with very large WC particles, most of the densification occurs only after liquid formation and it is likely that some large pores remain in the structure.

\section{Acknowledgements}

We thank to CNPq and OeAD for the partial financial support and to the Company Wolfram Bergbau \& Hütten $\mathrm{GmbH}$ for supplying the WC powders.

\section{References}

1. Goretzki, H.; Exner, H.E.; Scheuermann, W. Modern Developments on Powder Metallurgy, v. 4, p. 327, 1971.

2. Upadhyaya, G.S.; Bhaumik, K. Materials Science \& Engineering A, v. $105 / 106$, p. 249,1988 .

3. Dawihl, W.; Schroeter, K.Z. fuer Metallkunde v. 41, p. 231, 1950.

4. Exner, H.E.; Freytag, J.; Petzow, G.; Walter, P. Plansee Bericht fuer Pelvermetallurgie, n. 26, p. 231, 1978.

5. Bock, A. Post doctoral work: on grain growth of ultrafine WC during powder carburization and hard metal sintering, Institut fuer chemische Technologie anorganischer Stoffe, Technische Universitaet Wien, 1995.

6. Snowball, R.F.; Milner, D.R. Powder Metallurgy, v. 11, n. 21, p. 23, 1968.

7. Nelson, R.J.; Milner, D.R. Powder Metallurgy, v. 14, n. 27, p. 39, 1971.

8. Nelson, R.J.; Milner, D.R. Powder Metallurgy, v. 15, n. 30, p. 336, 1972.

9. Meredith, B.; Milner, D.R. Powder Metallurgy, v, 1, p. 38, 1976.

10. da Silva, A.G.P. Doctoral Thesis: Study on sintering and grain growth of WC-based hard metals, Institut fuer chemisch Technologie anorganischer Stoffe, Technische Universitaet Wien, 1996. 